\title{
Understanding Muslim Consumers Halal Food Consumption Intention
}

\author{
WESAM EID \\ Kenichi Ohmae Graduate School of Business - Business Breakthrough University. \\ Email: wesam.m.eid@gmail.com
}

\begin{abstract}
In the field of consumer behavior, religion is considered as an important cultural element. It influences consumers' beliefs, values, and behavior. Religion can play an important role in deciding food purchases and establishing food habits as seen in the Muslim consumption of halal food. This created an increase in the interest in Muslim consumers and the Islamic market. This interest is due to the rise in buying the power of Muslim consumers, an increase in their disposable income and a growing number of successful Muslim entrepreneurs. This study responds to the demand for more research in the area of Islamic marketing and contributes to the growing pool of data available for marketers and managers for planning future marketing strategies. It also addresses the subject of Muslim consumers and halal food in Japan, in response to the global halal phenomenon. The main objective of this study is to analyze intentions and attitude towards the consumption of halal food using the Theory of Planned Behavior (TPB.) By outlining the foundations of the Islamic market, it provides information for Japanese businesses to take the first steps in order to formulate effective marketing strategies to target this market. The findings show that Islam is an important factor that influences Muslim consumer decision-making. Results also show that attachment plays a significant role in influencing Muslim consumers' intention and attitude towards the consumption of halal food.
\end{abstract}

Keywords: Halal Food, Muslim Consumes, Religion, Theory of Planned Behavior (TPB), Islam, Consumer Behavior, Decision Making.

\section{Introduction}

Consumer behavior is the study of individual decision-making when purchasing, using, and disposing of products, services, ideas, or experiences to satisfy needs and desires (Solomon, 2004). As individuals and decision-makers, consumers are influenced by internal and external factors. Personal aspects such as age, lifestyle, occupation, and income; psychological factors like motivation, beliefs, and attitude. External factors like cultural, including religion and social class; and social, involving family, reference groups, role, and status. Religion is an important cultural component acknowledged by marketers and researchers. It influences consumers' beliefs, values, and behavior. Existing data on this subject, i.e. the study of marketing and consumer behavior of Muslim consumers and the Islamic market, remains insufficient. The earliest research examining religion's influence on consumer behavior began in the mid-1970s (Minton, 2015). It focuses on whether religion is a viable segmentation variable and makes connections to ethical behavior derived from religious scriptures.

Religion affects the consumer's decision-making process and intention to purchase and consume certain products and services. For macro-marketers, religion influences the process of economic pursuits including marketing. The prohibition or promotion of certain products, i.e. exclusion of alcohol in Muslim markets and the fostering of halal food consumption, can be affected by religion. On a micro-marketing level, 
religious affiliation, that is the consumer's beliefs and religiosity, or the extent to which a consumer's beliefs influence his or her behavior, also have an impact on economic activities. In deciding food purchases and establishing food habits, religion can play a powerful role, as seen in the Muslim consumption of halal food and Jewish consumption of kosher foods.

The Islamic market represents $23 \%$ of the world market. It is expected to grow to represent $26 \%$ of the world market by 2030 (Hughes, 2012). Therefore, Muslim consumers and the Islamic market represent viable and profitable business opportunities for various industries. The expanding Islamic market has motivated companies to address the needs of Muslim consumers. This market expansion is a result of a growing Muslim population, a rise in overall consumption, and an increase in disposable income. Thus, many companies have recognized the market potential, starting a global trend towards halal (lawful or permitted in Islam) products and services. The annual growth of halal food consumption represents $16 \%$ of global consumption. The halal market is estimated to be worth $\$ 667$ million and represents $20 \%$ of the global food market (Hughes, 2012). The demand for halal food is expected to increase by more than $70 \%$ by 2050. This demand has motivated companies to provide halal products for their consumers. For example, Nestle, by expanding its halal product lines to address the needs of Muslim consumers, has become the biggest food manufacturer in the halal industry claiming $\$ 5$ billion of annual global sales. As Muslim tourist expenditure continues to increase, furthering the ongoing success of halal tourism (catering to the needs of Muslim consumers in accordance with Islamic law), and representing a substantial chunk of the global outbound tourism market (Hughes, 2012), companies need to focus their efforts on acquiring information necessary to better understand and formulate their policies towards this growing market.

Muslims are known as the "Fourth-Billion" consumer segment, after India, China, and women, and show a strong foundation for future growth (Bikramjit \& Halder, 2015). The market for shariah-compliant products and services, that is products or services that conform to Islamic law, total $\$ 2$ trillion annually and is growing rapidly. While many Muslim consumers' lives are defined by the dietary, lifestyle, and financial rules of the Islamic faith, they are not a homogeneous whole (Bikramjit \& Halder, 2015). The recent interest in the field of Islamic Marketing is due to the appearance of several attempts in journals, articles and at conferences in a push to comprehend marketing proposals based on a framework of the principles of Islam and the context of the Muslim population. Islamic Marketing has gained prominence over the last decade because of the shifting demographics within the Muslim population, an increase in the purchasing power of the community, and the increasing number of Muslim entrepreneurs. This growing market segment, with its $\$ 200$ billion spending propensity in the US alone, is viewed by companies as an attractive avenue for economic growth. In addition, Muslim consumers are inclined to show extreme loyalty towards specific brands, freely advertising a brand's values via positive word-of-mouth networks (Mabe, 2011). Islamic Marketing represents a new and innovative strain of marketing that is a "focal phase torchbearer." It challenges convention but at the same time remains fit for the purpose of marketing. Hence, the concept of a Muslim market is in many ways vague (Bikramjit \& Halder, 2015.)

Japan is renowned for providing high-quality services with its service sector accounting for three-quarters of the country's total economic output (Global Finance, 2013). Generating millions of jobs domestically and with a global ranking of 4th for Travel \& Tourism GDP (World Tourism Organization, 2017), Japan has seen a steady rise in international visitors. In 2012, Japan was the third most-visited country in the Asia Pacific region, in 2013, Japan received 11.25 million visitors (World Tourism Organization, 2013). Between 2015 to 2016 Japan saw a $22 \%$ increase in international tourists to 24 million and has set targets of 40 million by 2020, and 60 million by 2030, which they have already exceeded (World Tourism Organization, 2017). Muslim tourist expenditure is expected to increase by $13 \%$ of the entire global tourism expenditure by 2020. The service sector is aiming to address the needs of Muslim consumers by providing prayer facilities and serving halal food at restaurants. These additional services have been a boon to the promotion of halal tourism (catering to the needs of Muslim consumers in accordance with Islamic law), which represents $12.3 \%$ of the global outbound tourism market (Hughes, 2012). In addition, the halal industry is one of the biggest and fastest growing industries in the world. The annual global market is 
around \$2.1 trillion, $60 \%$ of which is generated by halal food (Khalek \& Ismail, 2015). This growing demand of Muslim consumers creates and generates business opportunities for companies that are able to articulate this growing market segment. World leaders in the fast-food industry, such as KFC and McDonald's, have introduced halal food items to their menus. Accordingly, retailers like Carrefour and Albert Heijin have also introduced halal meat to their product lines (Arrnitage \& Conner, 2011.)

\section{Why Japan is Targeting Muslim Consumers}

Japan has been aiming to increase the number of tourists to 20 million visitors by 2020 , when Tokyo will host the Olympics Games (Singleton, 2014). In 2013, 11.25 million tourists visited Japan, a number $27 \%$ higher than in 2012 (Holliday, 2014). This increase in the number of tourists to Japan is largely due to the economic growth of neighboring Asian countries and other Southeast Asian countries (Holliday, 2014). The Islamic market represents $23 \%$ of the world market (Temporal, 2011), therefore, targeting this market creates opportunities for different industries such as tourism, hospitality, and the food and beverage industry. Japan has intensified efforts to increase the number of tourists and meet the demands of the Islamic market, garnering huge potential gains and allowing for new economic growth in the country (Tang, 2014). With the increasing numbers of tourists from Islamic countries, Japan's courtship of Muslim tourists started by providing prayer rooms, halal food restaurants and most importantly, establishing the Japan Halal Association. Founded in 2012, it issued 40 halal certificates to different restaurants around Japan (NY Daily News, 2014). This rising interest in meeting the demands of Muslim tourists is in response to the rising number of tourists visiting Japan from different Islamic countries, in addition to the rise of the middle class in Southeast Asia, and finally the influx of different Muslim athletes and audiences that the hosting of the Olympics Games in Tokyo will bring to Japan (NY Daily News, 2014.)

\section{Japan's Popularity Among Muslim Tourists.}

The total number of tourist arrivals in Japan in 2016 exceeded 24 million, ahead of the 20 million-target set by the national government for 2020. Tourists from Muslim nations accounted for a growing number of the arrivals. According to the Japan National Tourism Organization (JNTO), nearly 271,000 Indonesians traveled to Japan in 2016, up from just 63,000 in 2009 (Shusuke, 2016). Similarly, more than 394,000 Malaysians arrived in 2017, up from 89,000 of the previous year (Shusuke, 2016). The increase in the number of tourists from Southeast Asia is a result of several factors; the Japanese government relaxing visa requirements, growth in low-cost-carrier airlines serving Japan, an increase in the middle class having a larger disposable income, and better exchange rates making it easier for travelers to enjoy Japan. Although the Japanese government is intensifying their efforts to attract Muslim consumers, this is not the main reason that Japan has become an attractive destination for Muslim travelers. Japan is very well known for its extraordinary services, products, and technology, but also for a modern culture deeply ingrained with a traditional past.

Modern culture in Japan retains many historical traditions. Habits such as food rituals, daily religious practices, ancestor worship, and observing festivals are characteristics that Muslims respect and empathize with. Whilst many Japanese customs remain traditional, coexisting pop culture of economic importance thrives. A combination of anime, comics, video games, robotics, and offshoots of Otaku/geek culture and popular culture is a huge drawcard for many visitors to Japan. The anime industry alone nets substantial international profits, overseas sales in 2008 totaled $¥ 13.3$ billion, and continues to grow in popularity (Nagata, 2018). Japan's social and cultural environment is community centered. Low crime rates and strong neighborhood inter-relations have helped Japan to build a reputation of safety and trust (Kyodo, 2018), traits that many Muslims value and identify with. When compared to other destinations, Japan is viewed as a favorable tourist spot with modern conveniences, language options, and an infrastructure that encourages visitors to explore. This positive reputation overlaps the service industry, particularly in hotels. Hotels in Japan provide Muslim-friendly facilities, English language services, high levels of hygiene, and a willingness to satisfy and cater to tourist needs. 
Furthermore, Japan's reputation in the retail industry is trustworthy and of high quality. The "Made in Japan" seal of approval communicates a strong sense of value and legitimacy. Japan's retail industry is extensive, accounting for about 55\% of the Asian retail industry (Japan Retail News, 2018). Cultivating this secure and trustworthy reputation serves to increase Japan's attractiveness for Muslim tourists wanting to shop. With the establishment of Japan Halal Certification, implementation of Halal Media Japan and a myriad of Halal mobile apps, Japan entices Muslim tourists with the promise of safety, service, convenience, and tradition.

Previous literature (Bonne et al., 2007, Salman and Siddiqui, 2011, Nutrition Unit, 1993, Abdul Khalek and Syed Ismail, 2015) has articulated the topic of halal food consumption from a theoretical and empirical perspectives in different contexts and societies. Several studies have touched on the topic of halal food consumption by applying the Theory of Planned Behavior (TPB). The Theory of Planned Behavior is a theory that explains human behavior by linking beliefs to behavior. Developed by Icek Ajzen (1985), TPB states that attitude towards behavior, subjective norms, and perceived behavioral control come together to shape an individual's behavioral intentions and behaviors. Attitude represents a complex amalgamation of negative and positive reactions to behavioral outcomes. Subjective norms are the perception of behaviors and whether they are influenced by external factors like family, friends, and others. Perceived behavioral control is the individual's perceived ease or difficulty of performing the behavior of interest. Previous researchers (Abdul Khalek and Syed Ismail, 2015, bonne et al., 2007) have tested the influence of attitude, subjective norms, perceived behavioral control and religiosity on halal food consumption.

The main objective of this study is to analyze Muslim consumers' intentions and attitude towards the consumption of halal food by employing the Theory of Planned Behavior (TPB) with regard to the Japanese market. This research provides an insight on the growing interest in Muslim consumer behavior. It also brings about a clearer understanding of the halal phenomenon in Japan. It offers valuable information for companies wanting to plan and implement steps for providing halal food options and services. This study responds to the burgeoning need for more research on Islamic marketing, Islamic markets, and Muslim consumers. The increase in Muslim buying power and the rise of the middle class has made it necessary to understand and strive to meet the demands of Muslim consumers through the provision of services and products. This study addresses the topic of Muslim consumers and halal food in Japan, in response to the global halal phenomenon. This research focuses on Japan, as the country is expecting to receive an influx of Muslims visitors for the 2020 Tokyo Olympics and hopes to articulate this as an ongoing market segment. From the period of September 2016 to February 2017, Japan received 26,700 tourists from Malaysia and 17,900 tourists from Indonesia (Japan Tourism Research \& Consulting Co., 2017) and this number is expected to increase. This research aims to provide an understanding of Muslim consumer halal food requirements by implementing the Theory of Planned Behavior (TPB.) TPB has been chosen as it helps in understanding the determinants of halal food consumption in Japan.

\section{Literature Review}

In 1985, Ajzen introduced the TPB model as an extension of the Theory of Reasoned Actions (TRA). The TRA is widely used as a prediction of behavioral intentions or behavior. The TRA states that "behavioral intentions, which are the immediate antecedents to behavior, are a function of salient information or beliefs about the likelihood that performing a particular behavior will lead to a specific outcome" (Madden, Ellen , \& Ajzen, 1992). The TRA is used to explain the relationship between attitude and behaviors and predicts behavior in a specific context. However, the TRA does not include how individuals have incomplete volitional control. Henceforth, with this modification formulating the Theory of Planned Behavior (TPB) argues that behavior is affected by pre-existing attitudes, subjective norms, and perceived behavior control. Ajzen (1991) explains that the center of a behavior is the intention, thus, it captures the motivational factors that influence a behavior. These factors include the individual's attitude, willingness, efforts, motivation, and availability to perform a behavior. In general, an individual's strong intention to perform a behavior reflects how the behavior is performed. Perceived behavioral control is one's perception of the ease or 
difficulty of performing said behavior. In other words, attitude is the tendency of performing a behavior with a degree of favor or disfavor. Subjective norm is the social pressure placed upon the individual and its relation to the performance of the behavior intended. Finally, perceived behavioral control is the perception of the control the individual has about performing the behavior intended (Bonne et al., 2007).

The TPB explains that behavior is determined by the individuals' intent to perform the behavior. The intention to perform is affected by attitude towards the behavior. Subjective norms or social norms are about performing the behavior and the perceptions of whether the individual is able to be successfully involved in the targeted behavior. Subjective norms are the individual's perceptions on whether they can perform the behavior as influenced by their peers to perform the recommended behavior. Attitude is affected by beliefs, while norms are influenced by normative beliefs and motivation to fulfill the behavior. Perceived behavioral control is informed by belief that an individual possesses the opportunities and resources needed to engage in the behavior (George, 2004).

Attitude has a significant role in explaining the intention to perform a behavior. When consumers have positive attitude towards a behavior, consumers form the intention to perform a behavior. The importance of attitude on behavioral intention might be influenced by cultural characteristics, for example in collective societies when intention is more focused on the expectations of others and the behavior of the group rather than individuals. This type of attitude is less effective in predicting the behavior of the individual. Religion is reported to have an effect on attitude formation among believers (Bailey \& Sood, 1993). Intrinsically religiously motivated individuals are reported to have distinct systems of beliefs and attitude.

Ajzen (1991) finds no obvious "pattern in subjective norms" contribution in most previous TPB applications. Studies show the effect of subjective norms is either significant or the weakest predictor of a behavioral intention. However, subjective norms are utilized in this study because most Islamic communities are collective societies. Additionally, the Islamic religion encourages relationships of respect with parents and other family members. The importance of peer influence on individual decision-making is closely related to the culture of the society that the individual grew up in. In some cases, social pressure is an important factor among individuals living in collective societies. Some Muslim communities, such as Malaysia and Saudi Arabia, are reported to have collective society values. Thus, it is expected that peer pressure or social pressure has an effect on decision-making.

Perceived behavioral control refers to the individual's perception of ease or difficulty in performing a particular behavior. Ajzen (1991) suggests that when one sees obstacles in performing a behavior, they tend to perceive having incomplete control over the performances of that behavior. This is reflected in the individual's perception of having less than complete control over performing the behavior, and the significant effect of perceived behavior control in performance of the behavior. Perceived behavioral control applies in this study because Muslims tend to have varied levels of motivation to perform the religious directives regarding halal food. In addition, Muslim consumers who live in other religious societies, such as the US, England, and France, have more complete control over intentions to consume halal food as it is sold in more outlets. Ajzen (1991) argues that perceived behavioral control represents the individual's motivation to perform a behavior based on their confidence in performing the behavior and the presence of opportunities and resources to perform the behavior.

Several studies have assessed the importance or the impact of religion on consumer behavioral intention (Bonne et al., (2007); Delener, (1994); Abdul Aziz \& Chok, (2013)). Peterson and Roy (1985) stated that religion functions as a source of meaning and purpose that provides explanation on how to do things. For instance, Islam offers frameworks on how to deal with food and beverages, marriage and divorce, and inheritance. Hayat et al. (2015) implemented the TPB to identify elements of halal purchase intention and which elements had the most impact on purchase intention. The research conducted a survey on 300 Muslim consumers in Pakistan. The results show that when it comes to the halal market, personal and social perceptions have a higher effect on purchase intention than religious beliefs (Hayat et al., 2015). In 
addition, Khalek and Ismail (2015) tested the TPB to examine the determinants that influence generation Y of Muslims intention to consume halal food in Malaysia. The study shows generation $\mathrm{Y}$ is influenced by their attitude and subjective norms. A positive attitude towards halal food is the main motive for consuming halal food (Khalek \& Ismail, 2015).

The TPB has been implemented in many studies to identify consumer behavior intentions towards eservices. Pavlou and Fygenson (2006) extended the Theory of Planned Behavior to explain the process of e-commerce adoption by consumers. They captured the process by tracking two online consumer behaviors: first, getting information, second, purchasing a product from an online vendor. They found that trust, product value, and perceived usefulness and ease of use were important variables for predicting ecommerce adoption. Liao et al. (2007) implemented the Theory of Planned Behavior and disconfirmation model to predict and explain the individual's continuing use of online services. They found that customers' behavioral intention towards e-services was determined by customer satisfaction and affected by perceived usefulness and subjective norms. Hansen et al., (2004) tested the ability of TPB and TRA in predicting consumers' online grocery buying intentions. They conducted a survey of both Danish and Swedish consumers using a self-administered survey. They found that the TPB provided the best fit in predicting consumers' online grocery buying intentions.

To test the impact of religion on the daily lives of Muslims, Bonne et al. (2007) conducted a study utilizing the TPB to identify determinants that affect halal meat consumption in France. The study included habit as an independent variable of the TPB as it was previously proven to be an affective component (figure 1.) The study conducted a survey among 576 Muslims in France. The study concluded that positive attitude, social influence, and perceived behavioral control determine the intention to consume halal food. They also found that the availability of halal food was not significant in halal meat consumption. Finally, social structures, such as people's origin, family and income, were factors that determined their halal dietary preferences.

Bonne et.al (2007) also discussed the role of religion as a factor that shapes Muslim consumer identities. They argued that individual adherence to Islamic law/ruling could influence the decision-making process concerning halal meat. In an earlier study by Bonne \& Verbeke (2006) it was found that a consumer who was strict about eating halal meat may be not strict about other religious perceptions. Conversely, consumers with a strong Muslim identity may be more inclined to follow Islamic rules and customs and be more open to other influences. Bonne et. al. (2007) also argued that in Islamic culture tend to be grouporiented and interdependent within the group, which might influence individual attitude.

Figure 1: Bonne et. al. Conceptual Framework Theory of Planned Behavior with Application to Halal Food Consumption

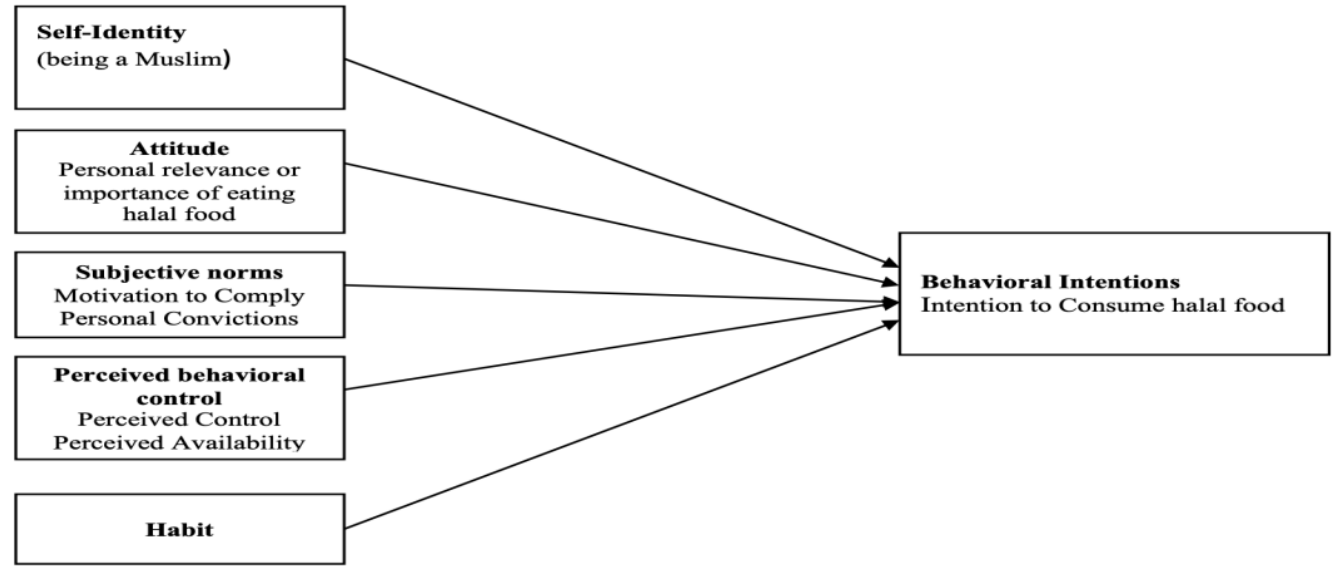

Source (Bonne et al. 2007) 
The TPB model states that attitude towards behavior, subjective norms, and perceived behavioral control shape an individual's behavioral intentions and behaviors. Several studies have implemented the TPB model in different industries to identify consumers' behavioral intentions or attitude. To more accurately reflect the Muslim consumer's intention towards halal food consumption a modified TPB model is suggested. Figure 2 explains how this new conceptual framework works in this study. The conceptual model suggests that Muslim consumers' behavioral intentions are influenced by three factors, subjective norms, attachment, and availability.

Similar to the TPB model, subjective norms refer to the belief of whether or not most consumers approve of the behavior. It relates to the consumer's belief about whether peers of importance to the consumer think the individual should engage in the behavior. Attachment is the new component introduced in this study modifying the TPB model. Attachment is an emotional binding that Muslim consumers have with their religion that also measures how much an individual complies with the rules. This can be measured through a consumer's level of adherence, religiosity, self-identity, habit, attitude, and perceived control towards the behavior.

Figure 2: Conceptual Framework of the Theory of Planned Behavior Applied to Halal Food Consumption

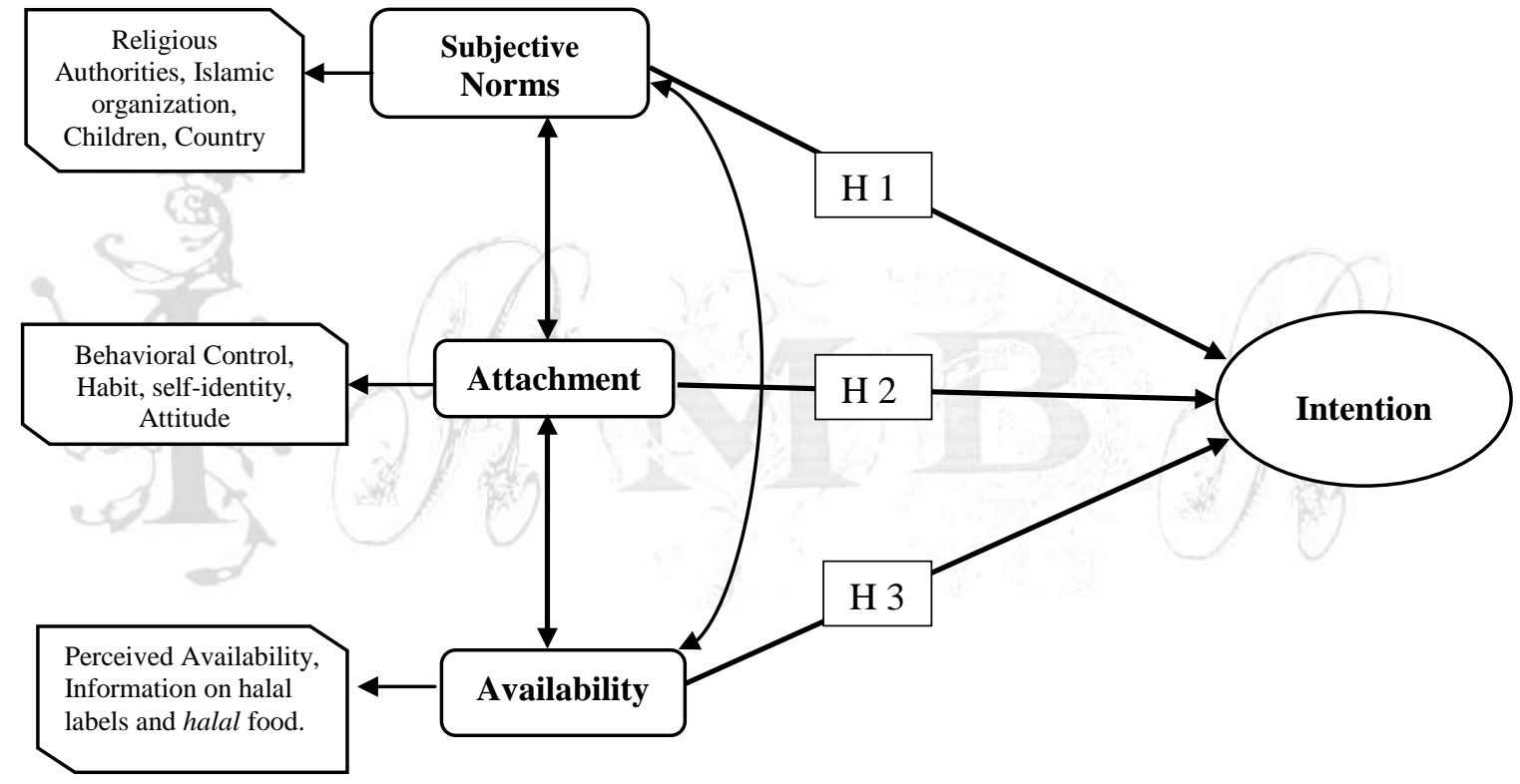

Attachment theory was introduced by Bowlby $(1969,1973,1980)$ to describe the relationship between infants and their mothers. Bowlby stated that "Infants emit social cues such as crying, smiling, and clinging to which a caregiver can be more or less attentive and vary in warmness." The same concepts of the theory were modified and applied in the field of psychology and sociology of religion. They examined the relationship with God as a source of attachment having an impact on the life outcomes of religious adherents (Kirkpatrick 1992; Kirkpatrick 1997). Those adhering to a religion may perceive God as being warm, responsive and a secure base during times of increased stress and perceived threat. For these individuals, God may be the perfect attachment figure that supersedes even the influence of the motherinfant relationship or compensates for the absence or lack of attachment to a parent. To Muslim consumers, attachment to their religion is a symbol of their religious adherence and religiosity. Religious attachment can affect the attitude of its followers. In Islam, these effects are very visible in consumers' daily activities, like praying and fasting. Attachment is a contributing factor in the behavioral intention of Muslim consumers given that some consumers' levels of attachment are stronger than others. Thus, attachment in this model identifies whether or not it is an influencing factor on intention. 
Bonne et.al. (2007) introduced perceived availability under behavioral control. They argued that consumers tend to perform a behavior that they feel they have control over and avoid performing behaviors that they feel they have no control over it. Thus, Bonne et.al. introduced availability as a factor that facilitates the performance of the behavior. Low availability of halal food might prevent consumption of halal food. When Muslim consumers relocate or travel for leisure, halal food might be scarce or unavailable, hence, availability is introduced as a dependent factor of the conceptual framework.

Therefore, the following hypotheses are proposed based on the conceptual framework.

H1. Subjective norms have a higher influence on Muslim consumers' intention to consume halal food.

H2. Perceived availability has a higher influence on Muslim consumers' intention to consume halal food than subjective norms.

H3. Muslim consumers' intention to consume halal food is positively influenced by their attachment to halal food thus affecting their decision-making.

\section{Methodology}

This research used the Bonne et al., (2007) research method. In this research, a structured questionnaire in Japan was used. The questions were adapted from Bonne et al., (2007) which are in support of the components of the proposed model. To measure the behavioral intention of the TPB, an eight-point Likert scale ranging from 1 to 8 asked, "How many times do you intend to eat halal food in the next few days, today included?" Attitude was measured through the statement "halal food is important to me" on a fivepoint scale ranging from "I totally agree" to "I totally disagree." This element serves as a motivational force to consume halal food. Subjective norms were measured with multiple elements to measure the motivation to consume halal food. For this objective, the question was, "To what extent do you take the encouragement to eat halal food of the following people or institutions into consideration?" On a five-point scale from "not at all" to "very much" respondents had to rate the influence of their partners, friends, family, religious authorities, children, country, and Islamic organization. To measure personal conviction, the statement "eating halal food is a personal choice" was used on a five-point scale ranging from "totally agree" to "totally disagree" Bonne et al., (2007).

The statement "How much control do you feel you have over-eating halal food?" tested perceived behavioral control. On a seven-point scale ranging from "complete control" to "no control." Perceived availability was measured with "Please state if you agree or disagree with the following" and, on a fivepoint scale, respondents stated if they agree or disagree with the following statements: "halal food is readily available", "There are a lot of choice possibilities in halal food", "Information on halal labels are clear", and "There is sufficient information available on halal food." Habit was measured with a five-point scale ranging from "totally agree" to "totally disagree" using the statement "Eating halal food is something that I do without reasoning." Self-identity was measured with the statement "I consider myself a Muslim" on a five-point scale ranging from "totally agree" to "totally disagree" Bonne et al., (2007). In addition to demographic factors, questions about age, gender, nationality and marital status were also asked Bonne et al., (2007).

\section{Data Analysis}

To test the accuracy of the results, a reliability analysis, employing Cronbach Alpha, has been conducted. The reliability test shows the consistency and accuracy of the data. If the association in reliability analysis is high, the scale will show consistent results and is therefore reliable. Reliability is significant at 0.7 or 0.8 ( $\alpha=0.8$ ). Table 1 shows that $\alpha=0.795$, which is close to $\alpha=0.8$. Thus, the data is reliable. 
Table 1: Reliability Statistics

\begin{tabular}{|c|ccc|}
\hline Variables & $\begin{array}{c}\text { Cronbach's } \\
\text { Alpha }\end{array}$ & $\begin{array}{c}\text { Cronbach's Alpha Based on Standardized } \\
\text { Items }\end{array}$ & $\begin{array}{c}\text { N of } \\
\text { Items }\end{array}$ \\
Subjective norms & 0.857 & 0.859 & 4 \\
Attachment & 0.594 & 0.638 & 4 \\
Availability & 0.717 & 0.719 & 3 \\
\hline
\end{tabular}

Table 2 shows the demographic characteristics of the respondents. Out of the respondents, 59.8\% were female of which there was a higher rate of halal food consumption than that of the male respondents. Male respondents represent $40.2 \%$ of the total sample. This table shows that female respondents tend to consume halal food more than male respondents.

The table also shows that the sample consists mainly of young respondents between the ages of 20 to 29 , which represents $47.1 \%$ of the respondents. Respondents between the ages 30 to 39 follow young respondents with $36.1 \%$. Respondents between the age of 50 to 59 and 60 to 69 represent the lowest percentage of respondents with $2.0 \%$ and $2.0 \%$ of the total sample size.

Table 2 also shows that Respondents from the Middle East represented $67.6 \%$ of the whole sample, followed by South East Asia and Far East with 16.7\% of the sample. Respondents from Africa represented $3.9 \%$, while respondents from North and South America represented $11.8 \%$ of the total sample size. Middle Eastern respondents represented the highest percentage of the total sample size due to Japan's positive image and the popularity of Japanese pop culture in Middle Eastern Countries.

Table 2: Demographic Characteristics of the Respondents

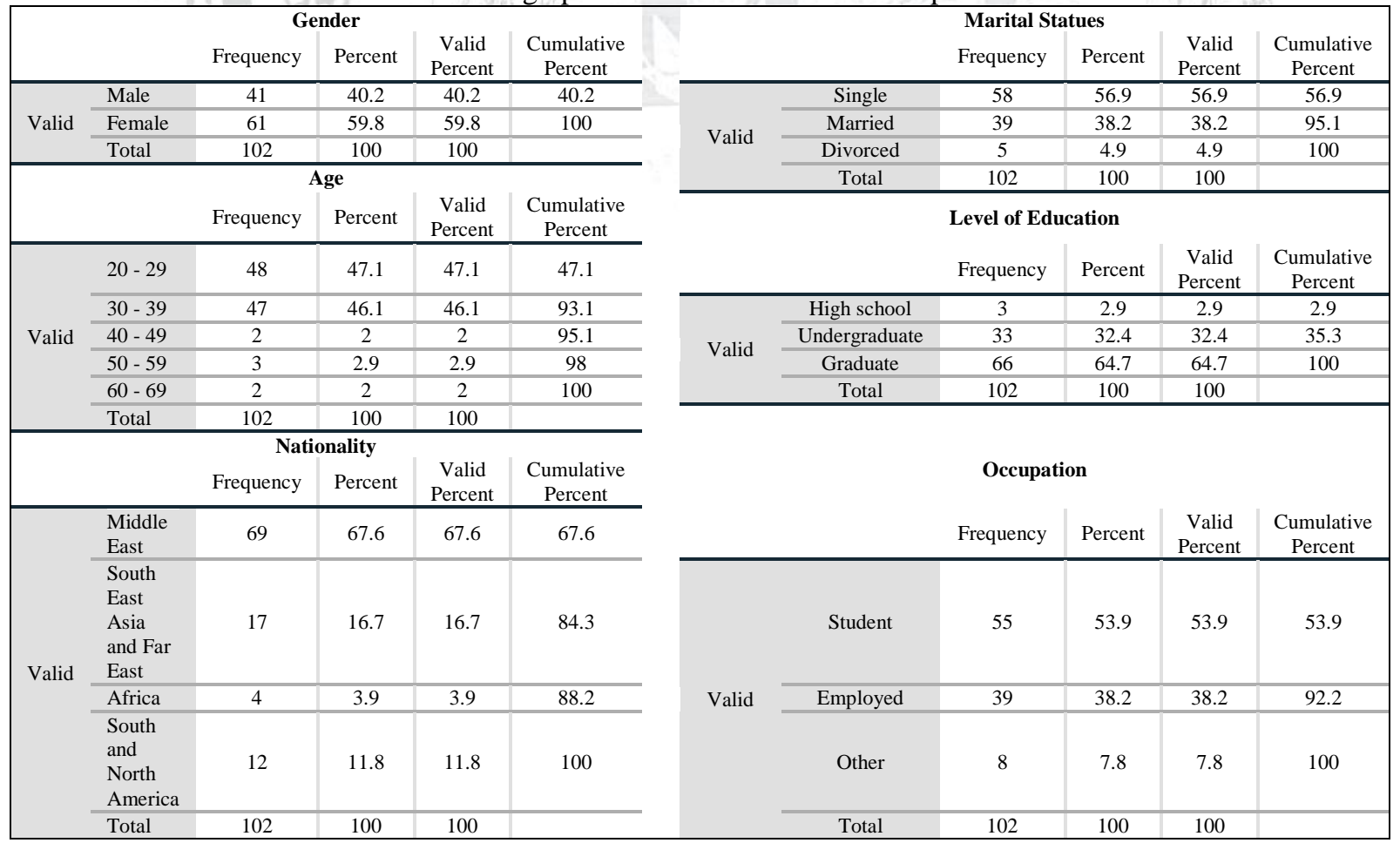


Relatively, more single (56.9\%) people completed the survey compared to the $38.2 \%$ of married respondents. Respondents with a divorced martial statue represented $4.9 \%$ of the total sample size. This shows that single and young respondents tend to visit or live in Japan more than married and divorced respondents. In addition, the respondents' occupations. $53.9 \%$ of the respondents are still conducting their studies, while $38.2 \%$ are employed. Others, such as housewife's, retired respondents, represented $7.8 \%$ of the total sample size.

Furthermore, table 2 shows the respondents level of education. $64.7 \%$ of the respondents were with a graduate degree and $32.4 \%$ were those that completed their undergraduate education. Respondents with a high school education represented $2.9 \%$ of the sample size.

Table 3: Regression Analysis of intention with subjective norms, attachment, personal choice, and perceived availability.

\begin{tabular}{|c|c|c|c|c|c|c|}
\hline \multirow{2}{*}{\multicolumn{2}{|c|}{ Model }} & \multicolumn{2}{|c|}{ Unstandardized Coefficients } & \multirow{2}{*}{$\begin{array}{c}\text { Standardized } \\
\text { Coefficients } \\
\text { Beta }\end{array}$} & \multirow[b]{2}{*}{$\mathrm{T}$} & \multirow[b]{2}{*}{ Sig. } \\
\hline & & B & Std. Error & & & \\
\hline \multirow[t]{5}{*}{1} & (Constant) & 6.284 & .204 & & 30.778 & .000 \\
\hline & Subjective norms & .366 & .205 & .153 & 1.784 & .078 \\
\hline & Perceived availability & .159 & .205 & .067 & .777 & .439 \\
\hline & Attachment & 1.195 & .205 & .501 & 5.822 & .000 \\
\hline & personal choice & .141 & .205 & .059 & .688 & .493 \\
\hline
\end{tabular}

Dependent Variable: intention

Table 3 shows the regression analysis results of the four factors identified. Table 3 indicates the statistical significance of the regression model that was run. Regression is significant when $\mathrm{P}<0.0005$, which is less than 0.05 , and indicates that, overall, the regression model significantly predicts the outcome variable.

Table 3 shows that Subjective norms is statistically insignificant with 0.078. In addition, attachment is significant at 0.000 , which is smaller than 0.05 . Thus, table 3 indicates that attachment influences Muslim consumers' intention to consume halal food.

Structural Equation Analysis (AMOS) shows the relationship between the dependent variable intention and independent variables attachment, subjective norms and attitude are tested. In the diagram shown below, correlations and covariance are represented by bidirectional arrows, which represent relationships without an explicitly defined causal direction. For instance, attachment, subjective norms, and availability are related.

Furthermore, attachment causes the scores observed on the measured variables perceived behavioral control, habit, attitude, and self-identity. Causal effects are represented by single-headed arrows in the path diagram. Attachment subjective norms, and availability are latent factors, whilst perceived behavioral control, habit, self-identity, attitude, children, country, Islamic organizations, religious authorities, perceived availability, information on halal food, and information on halal labels are observed variables (diagram 1.)

E1 through E12 are residual or error variances that also cause response variation in all observed variables. This diagram explains scores or responses on survey items one through eleven are caused by three correlated factors, along with variance that is unique to each item. Some of that unique variance might be due to measurement error. 
Diagram 1: Causal Model of TPB Components using AMOS

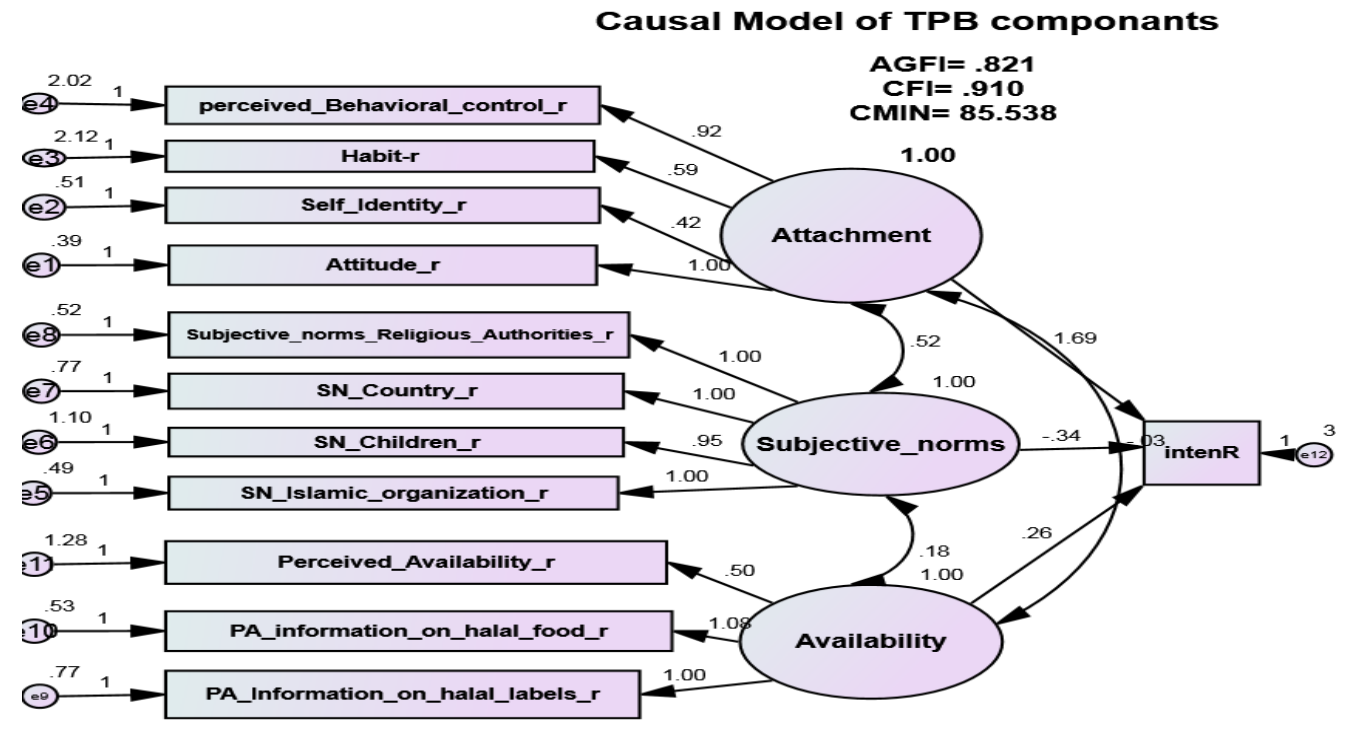

Table 4: Regression Weights: (Group number 1 - Default model)

\begin{tabular}{|c|c|c|c|c|c|c|c|}
\hline & & & Estimate & S.E. & C.R. & $\mathrm{P}$ & Label \\
\hline Attitude & $\begin{array}{ll}<-- \\
\end{array}$ & Attachment & 1.000 & & & & \\
\hline Self-identity & $<---$ & Attachment & .422 & .084 & 5.029 & $* * *$ & \\
\hline Habit & $<---$ & Attachment & .585 & .165 & 3.547 & $* * *$ & \\
\hline SN Islamic organization & $<---$ & Subjective Norms & 1.000 & & & & \\
\hline SN Children & $<---$ & Subjective Norms & .950 & .126 & 7.570 & $* * *$ & \\
\hline SN Country & $<---$ & Subjective Norms & .997 & .112 & 8.925 & $* * *$ & \\
\hline PA Information on halal labels & $<---$ & Availability & 1.000 & & & & \\
\hline PA information on halal food & $<---$ & Availability & 1.082 & .156 & 6.925 & $* * *$ & \\
\hline Perceived Availability & $<---$ & Availability & .501 & .132 & 3.801 & $* * *$ & \\
\hline intention & $<---$ & Subjective Norms & -.335 & .298 & -1.123 & .262 & \\
\hline Perceived Behavioral control & $<---$ & Attachment & .916 & .170 & 5.388 & $* * *$ & \\
\hline intention & $<---$ & Attachment & 1.686 & .320 & 5.270 & $* * *$ & \\
\hline intention & $<---$ & Availability & .260 & .240 & 1.081 & .280 & \\
\hline Subjective norms Religious Authorities & $<---$ & Subjective Norms & 1.002 & .100 & 10.058 & $* * *$ & \\
\hline
\end{tabular}

Table 4 displays the unstandardized estimate, its standard error (abbreviated S.E.), and the estimate divided by the standard error (abbreviated C.R. for Critical Ratio). The probability value associated with the null hypothesis that the test is zero is displayed under the $\mathrm{P}$ column. Table 4 shows the unstandardized factor loading, factor covariance and error covariance. The unstandardized estimate is statistically significant when C.R. value is >1.96. In table 7, the Critical Ratio C.R. for self-identity is 5.029 which is greater than 1.96, thus, self-identity is statistically significant. Furthermore, the C.R. of intention loading on subjective norms is -1.123 which is smaller than 1.96, thus, subjective norms has no significance effect on intention. In a similar manner, the C.R. for intention loading on availability is 1.081 which is smaller than 1.96 , therefore, availability has no effect on intention. In contrast, the C.R. of intention loading on attachment is 5.270 which is greater than 1.96 , thus attachment has a great influence on intention. 
Table 5: Covariance: (Group number 1 - Default model)

\begin{tabular}{|lll|lcccc|}
\hline & & & Estimate & S.E. & C.R. & P & Label \\
\hline Attachment & $<->$ & Availability & -.026 & .127 & -.203 & .839 & \\
Subjective Norms & $<-->$ & Availability & .182 & .117 & 1.551 & .121 & \\
Attachment & $<->$ & Subjective Norms & .515 & .097 & 5.333 & $* * *$ & \\
\hline
\end{tabular}

Table 5 shows the covariance of the TPB components. Similar to table 4, factor is considered statistically significant when C.R. is greater than 1.96. The C.R. of attachment and availability is -0.203 which is less than 1.96, thus, this factor loading is statistically insignificant. Subjective norms and Availability C.R. is 1.551 , which is less than 1.96 , thus making subjective norms and availability statistically insignificant. Finally, the C.R. of Attachment and subjective norms is 5.333, which is greater than 1.96, therefore, subjective norms and attachment are statistically significant.

Table 6: Model Fit Summary

\begin{tabular}{|l|lllll|}
\hline Model & $\begin{array}{l}\text { NFI } \\
\text { Delta1 }\end{array}$ & $\begin{array}{l}\text { RFI } \\
\text { rho1 }\end{array}$ & $\begin{array}{l}\text { IFI } \\
\text { Delta2 }\end{array}$ & $\begin{array}{l}\text { TLI } \\
\text { rho2 }\end{array}$ & CFI \\
\hline Default model & .806 & .753 & .914 & .886 & .910 \\
Saturated model & 1.000 & & 1.000 & & 1.000 \\
Independence model & .000 & .000 & .000 & .000 & .000 \\
\hline
\end{tabular}

\begin{tabular}{|l|llll|}
\hline Model & RMSEA & LO 90 & HI 90 & PCLOSE \\
\hline Default model & .080 & .048 & .109 & .060 \\
Independence model & .237 & .216 & .258 & .000 \\
\hline
\end{tabular}

Table 6 explains the model fit summary of the results in Amos graph. Table 6 shows that the hypothesized model fits the data very well as evidenced by the Goodness of Fit Index (GFI) of 0.910 and Root Mean Square Error of Approximation (RMSEA) of 0.080. Table 6 of the Amos output were chosen on the basis of their variant approaches to the assessment of model fit. GFI ranges from 0 to 1.00 , with values close to 1.00 being indicative of good fit. RMSEA values that are less than 0.05 indicate good fit, and values as high as 0.08 to 0.10 represent reasonable fit, however values higher than 0.10 show poor fit. As a result, the model summary fit shows that diagram 1 is a great fit for the data, thus, the hypothesized model is significantly appropriate.

The data shows that subjective norms and availability have no significant influence on intention thus hypothesis 1, which states that subjective norms have a higher influence on Muslim consumers' intention to consume halal food, and hypothesis 2 , which suggests that perceived availability has a higher influence on Muslim consumers' intention to consume halal food than subjective norms, are both rejected. The analysis also shows that Attachment is the only variable that is significant to intention. Thus hypothesis 3 states that Muslim consumers' intention to consume halal food is positively influenced by their attachment to halal food thus affecting their decision-making is supported.

\section{Conclusion}

This study seeks to analyze Muslim consumers' intentions and attitude towards the consumption of halal food by employing the Theory of Planned Behavior (TPB). The study focused on identifying determinants that influence Muslim consumers' halal food consumption intention in Japan by integrating a modified model of the Theory of Planned Behavior (TPB). The consumption of halal food for Muslim consumers has a large religious significance. This religious association with halal food makes this decision more important for Muslim consumers. Consequently, this could lead to a different decision-making process and factors influencing the intentions to consume halal food in Japan. This study adopted the Bonne et al., 
(2007) methodology to examine the results in a different context, i.e. Japan. Bonne et al., (2007) included habit and self-identity as components of the TPB model to understand the concept of food consumption under religious guidelines. Bonne et. al. (2007) stated that self-identity could be interpreted as a label that people use to describe themselves. They argued that "Islam refers to religious identity especially in a situation of foreignness." Thus, the extent to which an individual consider her/himself as Muslim might influence the decision-making process in regard to halal meat consumption. Bonne and Verbeke (2006) found that individuals can strictly follow the dietary rules and eat halal without following other religious rulings this is because these individuals consider themselves less as Muslims and are less motivated to follow religious rules or peer pressure, while they tend to follow their personal attitude. On the other hand, consumers with a higher identification as Muslims might be more motivated to follow Islamic rules and customs and consequently more open for peer pressure (Bonne and Verbeke, 2006). However, the question used to measure self-identity in this study proved to be inadequate as it caused confusion in responses, leading to inaccuracy in the results. A more thorough questions should be considered to improve clarity and accuracy of the findings.

Islam provides the individual not only with a specific set of acts and spiritual rituals but also with standards of behavior and a foundation on which consumers choose to lead their life. Islam has sets of laws that affect everyday purchases and habits. Even if the degree to which individual members adhere to religious conventions varies, their preferences and tastes are shaped by values according to the rules and customs of their religion. Religion is a crucial factor in shaping consumer consumption decision-making, attitude and intentions, especially, in regard to food choices. The findings of this study show that Muslims' halal food consumption intentions in Japan is determined by Attachment. The results show that positive attitude (grouped under attachment) towards halal food consumption is the most important factor influencing behavioral intention. As much as religion shapes an individual and their experiences growing up in their country of origin, external factors such as subjective norms and culture may play a crucial role in influencing behavior and attitude, within their own country. Growing up in an Islamic society where everything is halal by default, the decision-making process is markedly different to that for Muslim consumers when abroad. When Muslim consumers travel to other countries, like Japan, external influences such as subjective norms and culture significantly diminish or become possibly absent. The key determining factor at play is attachment, this component directly affect their behavioral intention.

Perceived behavioral control is significant and is supported by findings from Armitage and Corner (2011) and Bonne et al., (2007) who confirmed the significant influence of perceived behavioral control on consumer behavior. Findings of this study reveal that perceived availability has no significant influence on consumption intention. The halal food phenomenon in Japan is still in its early stages, so availability is low. The general assumption that it is unavailable, by Muslim consumers, makes it a non-issue and does not influence consumption intention. Halal food options exist, however limited and inconvenient, as do acceptable alternatives (fish, vegetarian), and consequently Muslim consumers choose to purchase or not purchase halal food based on their needs at the time. Furthermore, this study also shows that habit has no significant effect on intention. This is in line with the findings of Bonne et al., (2007) that states consuming halal food is not habitual in that it is a highly organized activity with a lot of thought behind it. Additionally, self-identity did not have a significant impact on intention. This is possibly due to the wide range of religious adherence of the respondents of the study and the inadequate phrasing of the question about self-identity.

This research paper is the first attempt to study determinants of Muslim consumers within the context of the Japanese environment. Japan's service philosophy and ethics go above and beyond the basic services offered by many countries, in that the host's sole aim is to discover and accommodate the preferences and desires of the guest to the utmost of their ability. This beginning of ongoing research is particularly important for Japanese companies considering starting halal product lines and businesses wanting to accommodate halal food preferences and availability for Muslim consumers. This research paper also benefits companies and businesses in Japan who aim to include or possibly target the Muslim market by 
offering halal food options and services to heighten the enjoyment and comfortability of their experience. By offering these culturally tailored services, they create a perception of value and thoughtfulness perhaps not offered by competitors; attracting customers and developing a brand trust reputation. Associating a brand or hotel with the idea that everything offered is halal, diminishes Muslim consumers' concerns about their ability to follow Islamic protocols when overseas, allowing them to better focus on enjoying their trip, or daily life, with some of the ease they experience in their country of origin. It may also reduce reluctance or hesitation to make requests or inquire after halal food by Muslim guests.

The Muslim market is homogenous in attitude towards the consumption of halal food, but heterogeneous when it comes to non-food products like cosmetics. Halal food, for Muslims, is a direct reference from the Quran, it is a static, unchangeable fact, not subject to fatwa rulings (a non-binding but authoritative legal opinion from a qualified jurist or scholar.) Muslim consumers' attitude towards halal food is a homogenous characteristic of the Muslim market. All Muslims share this common behavior/belief despite their backgrounds. When traveling, Muslims' attitude and behavior towards halal food does not change, unlike other characteristics such as dress code. To elaborate, women wearing hijab in their country of origin may adapt to local customs when overseas by not wearing a headscarf. In contrast, attitude towards halal food consumption does not undergo the same adjustment, perhaps due to expectations of unavailability in nonIslamic countries or the many varied food preferences already present in popular culture, i.e. veganism, gluten allergy. Additionally, Japan offers a predominantly seafood and vegetable-based diet and subsequently there are options available in the absence of halal food. Therefore, in the TPB model, availability is insignificant; if it is available satisfaction increases, if not, the consumer is still satisfied. Providing these excitement attributes adds to increased religious awareness and an overall increase in satisfaction for the Muslim tourist market in Japan. Identifying these homogenous traits, helps to establish a strong foundation for understanding the broader Muslim global market, from which businesses can further specialize and tailor experiences to the different heterogeneous Muslim market sectors.

The findings of this study show that demographic characteristics are insignificant. In this study, due to the small sample size, 102 respondents, it is difficult to conclude how demographic characteristics are significant. Middle Eastern Islamic nations may view the concept of halal differently to that of Islamic nations in South East Asia; halal predominately concerns food consumption and is not often extended to non-food products, unlike Malaysia (preference).

Regional differences between Muslim nations exist in attitude and intention towards non-food products versus halal food products. For example, a comparison of surveys with respondents from Saudi Arabia and the UAE, versus respondents from Malaysia, found that most respondents from the Middle East are less concerned with the halal status of non-food products (Rajagopal et. al., 2011). Results showed that between different Muslim regions "there is a significant difference between attitudes... (and) intention to buy Halal cosmetic products and intention to buy Halal food products." Regional differences in how Islam is perceived affects behavior; one's knowledge of Islam and how to behave are connected.

Discrepancies or variances of adherence to Islamic law between nations exist, but without a more thorough investigation and larger sample size, conclusions cannot be drawn here. The teachings of halal and haram apply equally to everybody regardless of age, gender, nationality or education. There are teachings in the Quran and Sunnah about the specifics of gender roles, often times it can be confused with the rituals of Islam. Gender roles are mostly influenced by culture rather than the religion itself. For example, in Saudi Arabia women are restricted more than men, evident in the separate education system for girls, whereas in Malaysia the education system is the same for both genders (Muhammed, 2008). Culture is defined as a way of life, specifically the general customs and beliefs of the populace of the time (Cambridge Dictionary, 2018). It embodies the characteristic features of everyday existence. The characteristics of culture are present in behavior, habits, morals and religious beliefs. Tse et al. (1988) defines culture as the "general tendencies of persistent preference for particular states of affairs over others, persistent preferences for specific social processes over others, and general rules for selective attention, interpretation of 
environmental cues, and responses." Culture is a component of behavior, not necessarily attitude. For instance, shariah law dictates that women wear hijab (headscarf), however, the way to wear it is not specified. Muslim women in the Middle East wear the hijab differently to their Indonesian counterparts, due to regional differences of the interpretation of this law. The Muslim attitude towards wearing the hijab is universal, but the behavior (style of wearing) or decision not to wear it (overseas travel) is cultural. Similarly, the attitude towards halal food remains universal, and the behavior or decision not to consume it is cultural.

The Quran addresses both genders equally without differentiating in its religious practices. Both men and women are obligated to pray, fast (Ramadan,) and follow Islamic edicts. The messages of Islam, namely peace and tolerance, righteous justice and ease of living/comfort, are for everyone regardless of distinction. Responsibility for providing for the household, the power to divorce, inheritance (double portion), and guardianship of the bride at weddings, falls to the man. Other than, in some elements of dress code, Islamic religion does not differentiate based on demographic characteristics; hence, the results of this research found that demographic characteristics are insignificant. However, further investigation of Muslims from geographical areas like the Middle East and South East Asia, to clarify differences in their decision-making process is recommended. There is no evidence in this study of the effect of the demographic characteristics on respondents in consumption intention. Level of adherence is not tested in this study, but might be affected by demographic characteristics (nationality,) therefore it is recommended for testing in future research.

Also, found to be insignificant were subjective norms. This is possibly because individuals are outside of their communities and peers are not present or are less so. This research found that attachment is significant, as it is connected to belief; the idea that God is everywhere. Levels of attachment are connected to the idea that halal food is cleaner, healthier and tastier (Al-Harran and Low, 2008). Lada et al. (2009) and Bonne et al. $(2007,2008)$ both stated that there is a positive relationship between attitude and intention to choose halal products, similarly, attachment has a positive influence on intention. Halal food consumption in Japan is mainly influenced by the individual's attachment to religious rulings.

This research provides a new insight of the Theory of Planned Behavior applied to halal food consumption intention, which suggests that Muslim consumers' intentions to consume halal food is influenced by subjective norms, attachment to the Islamic religion, and availability of halal food. This model proposes a new way of looking at how Muslim consumers make their decisions when it comes to food purchases/consumption. Through this model, we get a better understanding of how religion is a factor that influences Muslim consumers through their "Attachment." Islam is a way of life and is visible through dogma and shariah law. Where dogma deals with the spiritual aspects of life, shariah law deals with the practical. How Muslims attach to their religion is visible through the implementation of dogma and shariah law in their daily lives and habits. Through this proposed model, we take a step closer towards a deeper understanding of the way Muslims make their decisions.

There is a lack of research that focuses on Muslim consumer behavior, particularly in Japan, thus, this study is among the first studies that tackles the topic of Muslim consumers in Japan. It will benefit Japanese businesses who aim to target Muslim consumers. Furthermore, the increasing number of Muslim tourists to Japan in the last decade encouraged the Japanese government to enhance their efforts to provide services and products that cater to the Muslim population. Finally, there are various efforts by Japanese government and companies to promote Muslim-friendly facilities and service. Japan is cultivating the image tourists have of Japan to increase its attractiveness for Muslim tourists wanting to shop. With the establishment of the Japan Halal Certification, implementation of Halal Media Japan and advent of numerous Halal mobile apps as well as prayer facilities, Japan entices Muslim tourists with the promise of safety, service, convenience, and tradition. This research fills the need for more research in the area and contributes to a deeper understanding of the needs and requirements of Muslim consumers and the factors that influence 
their purchase intention of halal food. This understanding provides useful implications for Japanese companies and direction for further inquiry into marketing aimed at Muslim consumers.

\section{Managerial Implications}

This study shows that halal food is still an emerging market in Japan despite the fact that there is an increasing number of Muslim consumers either living in or visiting the country. The aim of this research is to contribute to the awareness of the demand for halal food.

As an implication of this study, increasing measures for Japanese businesses to provide more halal food options for Muslim consumers living and visiting Japan is recommended. As mentioned previously, due to the limited availability of halal food and the difficulty of acquiring it, perceived availability perhaps becomes a none-vital factor in halal food consumption. Provision of halal food options leads to an increase in satisfaction and as a result an increase in the ROI (Return on Investments) and a positive word of mouth.

Having a clear and firm grasp of the essence and knowledge of the Islamic market and halal food is also encouraged. It is important for marketers to comprehend the Islamic edicts of halal and haram and to comprehend the different sources of shariah law. This will assist marketers in developing effective marketing campaigns that are tailored to the specific needs of Muslim consumers when it comes to different products and services, such as cosmetics and fashion. In addition, marketing the availability of products and services that are specific for Muslim consumers in English is vital. English has become a universal language and most Muslim tourists in Japan face difficulties communicating and searching for halal options because of language barriers.

\section{Limitations}

This research is the first attempt to study determinants of halal food consumption in Japan with a focus on Muslim consumers. However, part of the limitation of this study is the small sample size. The findings of this study might not represent the larger population of Muslim consumers, thus, limiting the generalization of the findings for the general Muslim population. Although a large number of Muslims are living and visiting Japan, collecting the data proved challenging as many Muslim tourists declined to participate in the survey because it interfered with their travel plans. Therefore, the sample size used in this study is not sufficient to generalize the results for which a larger sample is required. Furthermore, the results given by the respondents, with the possibility of a more in-depth knowledge of the respondents' religiosity levels, may allow for different interpretations. In other words, the level of religiosity of each respondent may present different results. In addition, different theoretical models may be tested to give alternative perspectives of the results. The model proposed in this study may be modified to provide a better understanding of the data. The modified TPB model could include other characteristics as determinants of halal food consumption in addition to the items presented in this study, such as trust, obligation, involvement or values (Bonne et al., 2007).

The low significance of the results may also be attributed to the sensitivity associated with the topic of halal food. Thus, the phrasing of some of the survey questions might be responsible for this. Due to the sensitive nature of the topic, some questions related to subjective norms, self-identity, and personal convictions, if phrased differently, may have yielded different results. Questions concerning a person's religion is a very sensitive topic. Respondents may feel uncomfortable answering questions directly. Better phrasing of the questions might lessen the uneasiness of respondents allowing them to answer more honestly. In addition, the final question of the TPB model survey, "I consider myself a Muslim," is an insufficient measure of self-identity. A more appropriate question would be to ask Muslim consumers to state their level of agreement for the question, "I consider myself a good (devout) Muslim." It is possible that insufficient phrasing of this question caused confusion in responses, leading to inadequacies in the results. A more meticulous questionnaire design should be considered to improve clarity and accuracy of 
the findings. Furthermore, adopting the methodology of Bonne et al (2007) on 'self-identity' has been proven to be inadequate and needs more cautious consideration in order to avoid confusion and have a better understanding of the question.

\section{Recommendation for Future Studies}

Understanding Muslim consumers as the "fourth billion consumer segment.....in comparison to the other established, three-billion consumer groups: China, India, and women" (Alserhan \& Alserhan, 2012) is crucial because Muslim consumers group are not limited to one country, but are spread throughout different regions with different economies and cultures. In addition, addressing the needs of the Muslim segment drive global economic growth. Due to the lack of studies that address the needs, expectations, and Muslim consumers themselves, it is recommended that further research, focusing on identity and the different levels of religiosity within the Muslim market and with a closer look at these religiosity levels, be conducted to gain a more thorough understanding of their behavior. Additional studies of this nature extended to other Muslim countries, to determine whether local cultures play a part in determining service quality would serve as valuable comparative research.

Finally, this study shows that attitude and behavior towards halal food consumption is relatively similar regardless of different geographical locations. Future research might explore the topic of attitude and behavior towards different products, such as cosmetics and fashion, to identify more homogenous and heterogeneous aspects throughout the different populations of Muslim consumers. Further research is needed to identify the importance of Islam and shariah law for Muslim consumers and how this affects their behavior and decision-making. Possible future research on this topic with a focus on the extrinsic and intrinsic aspects of the way religion affects consumer behavior.

\section{References}

Aziz, A. Y. \&. (2013). The Role of Halal Awareness, Halal Certification, and Marketing Components in Determining Halal Purchase Intention Among Non-Muslims in Malaysia: A Structural Equation Modeling Approach. Journal of International Food \& Agribusiness Marketing, 25(1), 1 - 23.

Khalek, A. (2015). Why Are We Eating Halal - Using the Theory of Planned Behavior in Predicting Halal Food Consumption among Generation Y in Malaysia. International Journal of Social Science and Humanity, 5, 608 - 612.

Ajzen, I. (1985). From Intentions to Actions: A Theory of Planned Behavior. In A. I., Action Control (pp. 11 - 39). Berlin Heidelberg.: Springer.

Ajzen, I. (1991). The Theory of Planned Behavior. Organizational behavior and human decision processes, $50(2), 179-211$.

Al-Harran, S. (2008). Marketing of Halal Products: The Way Forward. . The Halal Journal, 44 - 46.

Alserhan, B. A. (2012). Researching Muslim Consumers: Do they Represent the Fourth-Billion Consumer Segment? . Journal of Islamic Marketing, 121 - 138.

Arrnitage, C. (2011). Efficacy of the Theory of Planned Behavior: a Meta-Analytic Review. British Journal of Social Psychology, 40(4), 471 - 499.

John, B. (1969). Attachment. In Attachment and Loss, Vol. 1. New York: Basic Books.

John, B. (1973). Separation. In Attachment and Loss, Vol. 2. New York: Basic Books.

John, B. (1980). Loss. In Attachment and Loss, Vol. 3. New York: Basic Books.

Bailey, J. (1993). The Effects of Religious Affiliation on Consumer Behavior: A Preliminary Investigation. Journal of Managerial Issues, 328 - 352.

Bikramjit, R. (2015). Demystifying the Islamic Consumer Segment. In R. Bikramjit, Islamic Perspectives on Marketing and Consumer Behavior: Planning, Implementation, and Control (pp. 214 - 230). USA: Business Science Reference.

Bonne, K. (2006). Muslim Consumer's Motivations Towards Meat Consumption in Belgium: Qualitative Exploratory Insights From Means-end Chain Analysis. Anthropology of food, 1 - 18. 
Bonne, K. V.B. (2007). Determ inants of Halal Meat Consumption in France. British Food Journal, 109(5), $367-386$.

Cambridge Dictionary. (2018, May 22). Meaning of Culture in the English Dictionary. Retrieved from www.dictionary.cambridge.org: https://dictionary.cambridge.org/dictionary/english/culture

Delener, N. (1994). Religious Contrasts in Consumer Decision Behaviour Patterns: Their Dimensions and Marketing Implications. European Journal of Marketing, 28(5), 36 - 53.

George, J. F. (2004). The Theory of Planned Behavior and Internet Purchasing. Internet Research, 14(3), $198-212$.

Global Finance. (2013, November 16). Japan Country Report . Retrieved from Global Finance : http://www.gfmag.com/gdp-data-country- reports/247-Japan-gdp-country-report.html\#axzz2rZiS203E

Hansen, T. J. (2004). Predicting Online Grocery Buying Intention: a Comparison of the Theory of Reasoned Action and the Theory of Planned Behavior. International Journal of Information Management, 24, 539 - 550.

Hayat M. \& Awan, S. A. (2015). Factors Affecting Halal Purchase Intention - Evidence from Pakistan's Halal Food Sector. Managment Research Review, 38(6), 640 - 660.

Holliday, K. (2014). Record Tourism Fuels Hotel Boom in Land of the Rising Sun. Retrieved from www.cnbc.com: http://www.cnbc.com/id/101333350

Hughes, R. (2012). Sharia indexes. International Journal for the Psychology of Religion, 2, 3 - 28.

Japan Retail News. (2018, March 28). Is Japan still an important retail market (in Asia)? Retrieved from Japan Retail News : http://www.Japanretailnews.com/Japans-retail-market.html

Japan Tourism Research \& Consulting Co. (2017, April 4). Japan-bound Statistics. Retrieved from Japan Tourism Research \& Consulting: http://www.tourism.jp/en/tourism-database/stats/inbound/

Lee, K. A. (1992). An Attachment-Theory Approach to the Psychology of Religion.

Lee, K. A. 1997. An Attachment Theory Approach to the Psychology of Religion.

Kyodo, (2018). Japan's crime rate hits record low as number of thefts plummets. . Retrieved from The Japan Times: https:/www.Japantimes.co.jp/news/2018/01/18/national/crime-legal/Japans-crime-ratehits-record-low-number-thefts-plummets/\#.WsTnsU

Lada, S. T. (2009). Predicting Intention to Choose Halal Products Using Theory of Reasoned Action. International Journal of Islamic and Middle Eastern Finance and Management, 66 - 76.

Liao, C. C.L. (2007). Theory of Planning Behavior (TPB) and Customer Satisfaction in the Continued Use of E-Service: An Integrated Model. Computers in Human Behavior, 23, 2804 - 2822.

Mabe, L. (2011). A new multicultural opportunity emerges: Carving out a $\$ 200$ billion, Macmillan.

Madden, T. E. (1992). A Comparison of the Theory of Planned Behavior and the Theory of Reasoned Action. Personality and Social Psychology, 3 - 9 .

Minton, E. A. (2015). In adverstising we Trust: Religisoty's influence on marketplace and relational trust. Journal of Advertising, 44(4), 403 - 414.

Muhamad, N. (2008). Muslim Consumers' Motivation Towards Islam and their Cognitive Processing of Performing Taboo Behaviors. Ph.D Dissertation. Australia: The University of Western Australia.

Nagata, K. (2018). Anime' makes Japan superpower. Retrieved from The Japan Times: https://www.Japantimes.co.jp/news/2010/09/07/reference/anime-makes-Japansuperpower/\#.WsTmzkxuLIU

News, N. D. (2014). Halal Tourism Growing in Japan as Country Tries to Attract Muslim Visitors. Retrieved from www.nydailynews.com: www.nydailynews.com: http://www.nydailynews.com/lifestyle/eats/halal-tourism-expanding-Japan-article-1.186172

Nutrition Unit. (1993). Socio-Cultural and Economic Factors Affecting Food Consumption Patterns in the Arab Countries. Public Health Directorate. Bahrain: Ministry of Health.

Pavlou, P. (2006). March). Understanding and Predicting Electronic Commerce Adoption: An Extension of the Theory of Planned Behavior. MIS Quarterly, 30, 115 - 143.

Peterson, L. \&. (1985). Religiosity, Anxiety, and Meaning and Purpose: Religion's Consequences for Psychological Wellbeing. Review of Religious Research, 27, 49 - 62.

Rajagopal, S. R. (2011). Halal Certification: Implication for Marketers in UAE. Journal of Islamic Marketing, 138 - 153. 
Salman, F. (2011). An Exploratory Study for Measuring Consumers Awareness and Perceptions Towards Halal Food in Pakistan. Nterdisciplinary Journal of Contemporary Research in Business, 639 - 651.

Shusuke, M. (2016). Japan doubles overseas tourist target for 2020. Retrieved from The Japan Times: https://www.Japantimes.co.jp/news/2016/03/30/national/Japan-doubles-overseas-tourist-target2020/\#.WsTpV0xuLIU

Singleton, J. (2014). Eating Halal: Japanese Cuisine Becoming More Accessible to Muslim Tourists. Retrieved April 13, 2017 , from www.nippon.com: www.nippon.com: http://www.nippon.com/en/nipponblog/m00044/

Solomon, M. R. (2004). Consumer Behavior: Buying, Having and Being. NJ: Allyn and Bacon.

Tang, S. K. (2014). How Japan is Courting Muslim Tourists. Retrieved December 14, 2014 , from www.cnbc.com: : http://www.cnbc.com/id/101890885

Temporal, P. (2011). Islamic Branding and Marketing: Creating a Global Islamic Business. Singapore: John Wiley \& Sons (Asia) Pte. Ltd.

Tse, D. L.H. (1988). Does Culture Matter? A Cross - Cultural Study of Executives' Choice, Decisiveness, and Risk Adjustment in International Marketing. Journal of Marketing, 81 - 95.

World Tourism Organization. (2017, March 20). UNWTO Secretary-General Welcomes Japan's Support for Tourism when Meeting with Prime Minister Abe. Retrieved December 4, 2017, from media.unwto.org: http://media.unwto.org/press-release/2017-03-20/unwt.

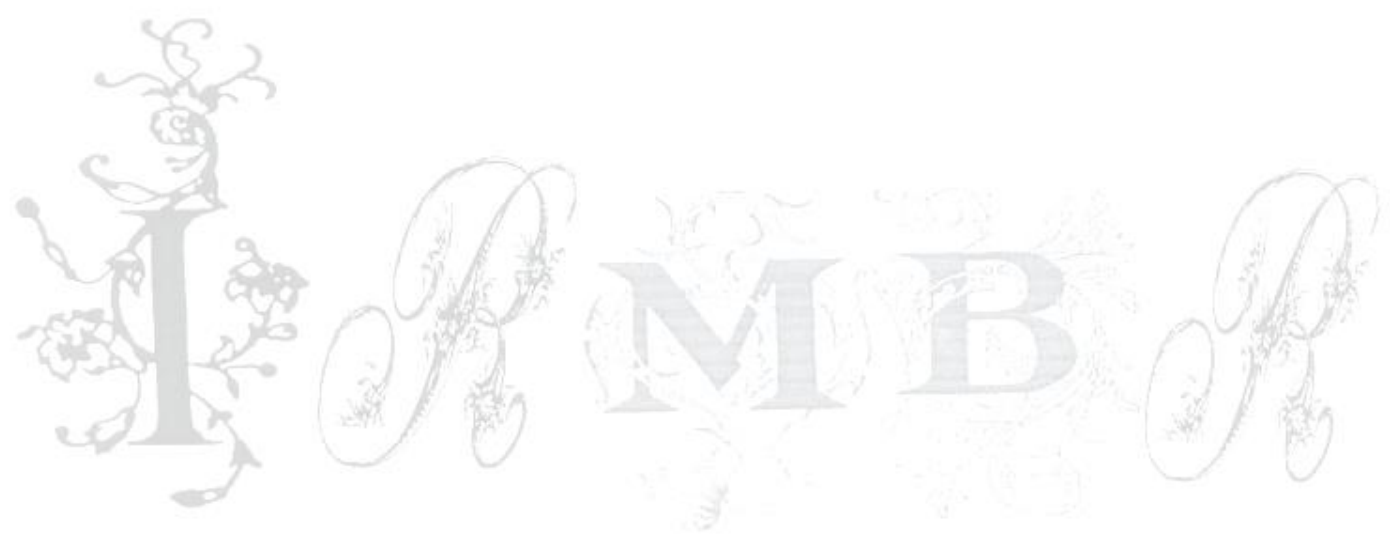

